\title{
Successful TB treatment outcome and its associated factors among TB/HIV co-infected patients attending Gondar University Referral Hospital, Northwest Ethiopia: an institution based cross- sectional study
}

Yenework Sinshaw ${ }^{1}$, Shitaye Alemu ${ }^{1}$, Abel Fekadu ${ }^{2 *}$ and Mucheye Gizachew ${ }^{3}$

\begin{abstract}
Background: Tuberculosis/Human immunodeficiency virus (TB/HIV) co-infection is bidirectional and synergistic which mainly affects interventions that have been taken on the area. Tb patients co-infected with HIV have poorer treatment outcome as compared to non-co-infected patients. There is limited information regarding successful TB treatment outcomes and its associated factors; a reason that this study was planned to investigate.

Methods: An institution based cross sectional study was carried out from July 2010 to January 2016. Data were abstracted from patients' medical chart using data abstraction format. The completeness of the data was checked and cleaned manually. Then, it was entered and analyzed by using SPSS version 20.0. Bi-variable and Multi-variable logistic regression model was fitted to identify factors associated with successful Tb treatment outcome. Significance was obtained through adjusted odds ratio with its $95 \% \mathrm{Cl}$ and a $p<0.05$.

Results: Successful TB treatment outcome among TB/HIV co-infected patients in Gondar University Hospital was 77.3\% [95\% Cl 72.6-81.9]. Being residing in outside the Gondar town [AOR $=0.44,95 \% \mathrm{Cl}: 0.25-0.80]$, having less than the mean baseline weight $(<43.7 \mathrm{~kg})$ at initiation of TB treatment [AOR $=0.51,95 \% \mathrm{Cl}: 0.29-0.89]$, being in the bedridden condition $[\mathrm{AOR}=0.23,95 \% \mathrm{Cl}: 0.1-0.23]$, and experiencing anti-TB treatment side effect [AOR $=0.35,95 \% \mathrm{Cl}: 0.12-0.98]$ were the factors that resulted the patient in treatment failure.
\end{abstract}

Conclusion: Successful Tb treatment outcome among TB/HIV co-infected patients was lower than the target set by Global Plan to Stop TB 2011-2015. Strengthening collaborative TB/HIV management activities that would trace the identified factors shall be recommended to increase successful treatment outcome of TB.

Keywords: Successful treatment outcome, TB/HIV co-infected patients, Tuberculosis, Ethiopia

\footnotetext{
*Correspondence: Fekten@yahoo.com

${ }^{2}$ Department of Epidemiology and Biostatistics, University of Gondar, Institute

of Public Health, Gondar, Ethiopia

Full list of author information is available at the end of the article
} 


\section{Background}

Despite various efforts made to prevent and/or control the disease, many countries have not yet achieved the TB control targets. Rather, it remains a major public health problem leading to mortality in high HIV- burden countries [1, 2]. HIV drives TB epidemic in many countries, especially in the sub-Saharan Africa, where $82 \%$ of the world's TB/HIV co-infection exists [3]. TB/HIV coinfection in one's body potentiate one another and hastening the weakening of the host's immunological functions. HIV co-infection is the most important risk factor for developing active TB, which increases susceptibility to primary infection, re-infection and/or reactivation for patients with latent $\mathrm{TB}$. TB also has a negative impact on the immune response to HIV, increasing the progression from HIV infection to acquired immunodeficiency syndrome (AIDS) [4].

Tuberculosis/HIV co-infection constitutes several problems including diagnostic and therapeutic challenges in the healthcare settings [5-7]. It is supported by a study conducted in USA that revealed treatment of TB in co-infected patients differ from those patients who are infected with TB only [8]. Some of these challenges: clinical problems about duration of treatment, frequency of drug administration, pill burden, management of drug interactions, and complications of therapy like drug toxicity and immune reconstitution inflammatory syndrome (IRIS). Since such patients are being treated for two infectious diseases, the goals of treatment for both must be balanced through therapy integration, use of concurrent Antiretroviral Therapy (ART), prevention of HIVrelated co-morbidities, controlling drug toxicity, and monitoring of IRIS $[2,4]$. This would bring optimal outcomes in terms of treatment response and prevention of drug resistance.

Among the 22 high TB burden countries, Ethiopia ranks $7^{\text {th }}$ with an incidence rate of 379 cases of all forms of TB per 100,000 populations. Continuous tracing of TB treatment outcome, mainly in those TB/HIV co-infected patients, is essential in the area $[9,10]$. However, in our study site, there was scarcity of recent data describing successful TB treatment outcome and its associated factors in TB/HIV co-infected patients [11]. Understanding its treatment outcome and associated factors in such a population may help in better management of TB. Therefore, this study assessed the successful TB treatment outcomes and its associated factors among TB/HIV co-infected patients attending the TB DOTS Clinic at the Gondar University Hospital, Northwest Ethiopia.

\section{Methods}

\section{Study setting and design}

The study was conducted at the Gondar University Hospital, Northwest Ethiopia, situated 738 kilometers far away from the capital. The Hospital serves over five millions of people from its catchment area (Amhara National Regional State Bureau of Health, Health Research Thematic Areas of Amhara Regional Health Bureau: Amhara Regional Health Bureau Health Research and Technology Transfer Core Process in collaboration with Ethiopian Network for HIV/AIDS Treatment Care and Support (ENHAT-CS) Amhara Region Program, Unpublished). An instituttion based cross-sectional analysis of successful TB treatment outcome among TB/HIV co-infected patients registered from July 2010 to January 2016 was conducted.

Gondar University hospital uses different types of TB diagnostic techniques like AFB microscopy or smear, X-ray, pathological, and Xpert MTB/RIF as required procedurally. TB DOTS clinic serves both adult and pediatric age groups with free drugs like Rifampicin, Isoniazid, Pyrazinamide and Ethambutol (2RHZE) for 2 months intensive phase with daily observation, and Rifampicin and Isoniazid (4RH) for 4 months continuous phase with monthly follow up for new TB patient. The hospital also provides Rifampicin, Isoniazide, Pyrazinamide, Ethambutol and Streptomycin (3RHZES) for 3 months intensive phase/, and Rifampicin, Isoniazide and Ethambutol (5RHE) for 5 months continuous phase for retreatment patients. For TB/HIV co-infected patients; they should take daily for 6 months; 2 months intencive phase taking Rifampicin, Isoniazid, Pyrazinamide and Ethambutol (2RHZE) and 4 months continuation phase taking Rifampicin and Isoniazid (4RH).

All $\mathrm{Tb}$ patients under treatment follow up were tested for HIV. For HIV screening, nationally approved rapid serological testing algorisms (KHB $\rightarrow$ StatPak $\rightarrow$ Uni-gold) were used. As soon as HIV is identified in a TB patient, the patient is enrolled to ART clinic and co-trimoxazole preventive therapy (CPT) started. The national TB/HIV implementation guideline recommends provision of ART for TB/HIV co-infected individuals if they are WHO clinical stage IV or CD4 $<350 / \mathrm{mm}$.

\section{Study population and sampling procedure}

The study population was all TB/HIV co-infected patients who attended at the Gondar University Hospital. TB/HIV co-infected patients who were transferred out to other health institution during the study period were excluded. The necessary sample size (n) was computed by single population proportion formula $\left(\left[n=\left[\left(\mathrm{Z}_{\mathrm{a} / 2}\right)^{2 *} \mathrm{P}\right.\right.\right.$ $\left.(1-\mathrm{P})] / \mathrm{d}^{2}\right]$ ) assuming $95 \%$ confidence level of $\mathrm{Z} \mathrm{a} / 2=$ $1.96,5 \%$ margin of error, and proportion (p) of $70.9 \%$ according to the previous similar study from Tigray region [12]. The calculated sample was 318 and by using correction formula the final sample size was reduced to 203. However, all TB/HIV co-infected patients' record at the Gondar University Hospital who started 
DOTs and had complete medical records on TB treatment outcome in the past 5 years were included in the study.

\section{Data collection and variable measurement}

Data were collected using pre-tested and updated data abstraction format. The format was developed by considering variables to be studied that found in the patient's TB/HIV treatment follow up chart and/or hospital registration book. Data collectors had a brief training that emphasized on inclusion and exclusion criteria of the study participants, and recording of the right information from the hospital registration book and/or patient's follow-up medical chart.

Clinical case and treatment outcome definitions were used according to the standard definitions of National Tuberculosis and Leprosy Control Program (NTLCP) [12] and WHO guideline [13]. Treatment outcomes were divided into (cured, completed treatment, defaulted/ interrupted, failed, died, and not evaluated). Successful/ favorable/good outcome were considered for TB patients who were cured (i.e., negative smear microscopy at the end of treatment and on at least one previous follow-up test) and/or completed treatment or sum of cases that cured and completed treatment [14].

Unsuccessful/unfavorable/poor outcome was considered for TB patients resulted in treatment failure, default or death [14]. Patients with documented treatment completion and resolution of symptoms, but not sputum smear microscopy available at the end of treatment were considered as completed treatment. Defaulted/Interrupted patient was a patient whose treatment was interrupted for two consecutive months or more for any reason without medical approval.

Patients with clinical and/or bacteriological signs of continued active disease or deterioration requiring a treatment change were considered as failed patients. Died patient is a patient who died for any reason during the course of treatment. A patient whose treatment outcome is unknown (including former "transfer out") was considered as not evaluated patients. A Patient who smoked at time of $\mathrm{TB}$ diagnosis or had history of cigarette smoking were taken as smokers and a patient who had never smoked in his/her life $[15,16]$ were taken as non-smokers.

Functional status was determined based on WHO guideline as follows; (a) Working = able to perform usual work in or out of the house, harvest, go to school or, for children, normal activities or playing (b) Ambulatory = able to perform activities of daily living but not able to work or play, and (c) Bedridden = not able to perform activities of daily living. Tb treatment side effect was ascertained by assessing and/or following of the patients' complain, and a comprehensive clinical history and additional medical exams along with different laboratory investigations including chemistry and hematocrit analysis.

Socio-demography of the patient (age, sex, economic status), concomitant condition (World Health Organization clinical staging, functional status), Biological factor (CD4+ Count), Patient Behavior (Smoking history), and medication related factor (History of TB treatment, drug side effect, ART) were collected as an independent variables of the study.

\section{Data quality}

Data abstraction checklist was pre-tested at Felege Hiwot Referral Hospital, which provides similar services to the TB/HIV co-infected patients prior to the commencement of the actual data collection. Data were collected by the trained data collectors with close supervision and assistant of the investigators. Completeness of the data was checked, coded and entered into the computer using SPSS version 20 statistical software on a daily basis. Each entry was cross checked independently to ensure the quality of data.

\section{Data analysis}

A total of $324 \mathrm{~TB} / \mathrm{HIV}$ co-infected patients were primarily enrolled in the study. Of this figure, 308 patients fulfilled the inclusion criteria and were analyzed. Descriptive statistics (mean (SD), proportion) aimed to summarize patients' characteristics across the outcome variables was used. Findings were described using words and tables. Association between successful TB treatment outcomes and each independent variable was analyzed using Bi-variable and Multi-variable logistic regression model.

The outcome was categorized as successful (cure + treatment completed) and unsuccessful (default, failure, death) treatment outcomes [14, 17]. All variables were entered into multivariable logistic regression using backward LR method to control confounding effect. Explanatory variables which had significant association with the outcome at $p$-value less than 0.2 in the bi-variable binary logistic regression were entered to multivariable logistic regression model to identify the predictors of successful $\mathrm{Tb}$ treatment outcome. Association between outcome and predictor variables was calculated using Adjusted odds ratio at $p$-value $<0.05$ and $95 \%$ confidence interval. Assumption of goodness of the model was checked by Hosmer-lemeshow test $(p=0.828)$.

\section{Ethical consideration}

Ethical approval was obtained from the Ethical Clearance Committee of the School of Medicine, College of Medicine and Health Sciences, University of Gondar prior to the commencement of the study. Confidentiality of the participants' information was maintained by giving 
participant's code number and the data locked in the cupboard and computer with password.

\section{Results}

Socio-demographic and behavioral characteristics of study participants

A total of $308 \mathrm{~TB} / \mathrm{HIV}$ co-infected patients record were analyzed in this study. Of these, 175 (56.8\%) were male. The mean age of the respondents was $31.7(\mathrm{SD} \pm 13.4)$ year. Two hundred and twenty nine (74.4\%) study participants were residing in the Gondar town, and 206(66.9\%) were ever married (married, divorced, or widowed) during their visits of the health institution. One hundred thirty three $(43.2 \%)$ had primary educational level (Grade 1 to $8^{\text {th }}$ ), 97(31.5\%) were daily laborer, and 264(85.7\%) had no history of cigarette smoking (Table 1$) \cdot$ th=tlb=

\section{Concomitant, biological and medication related factors of} the study participants

One hundred and ninety five (63.3\%) respondents had $<200 \mathrm{CD} 4 \mathrm{cell} / \mathrm{mm}^{3}$ at initiation of their TB treatment. The mean baseline weight at entry of TB treatment was $43.7 \mathrm{~kg}$. Six hundred sixty three $(52.9 \%)$ of the study participants have been found to be on working functional status. Two hundred seventy four patients (88.9\%) were on Co-trimoxazole Prophylactic Treatment (CPT), $188(61.0 \%)$ on ART, and $188(61.0 \%)$ were categorized as WHO clinical stage III during the initiation of their TB treatment. In addition, 231(75.0\%) respondents had not history of TB treatment, 219(71.1\%) had Pulmonary tuberculosis (PTB), and 290(94.2\%) had no TB treatment side effects (Table 2).

\section{Successful TB treatment outcome of the study participants}

As shown in Table 3, of the $308 \mathrm{~TB} / \mathrm{HIV}$ co-infected patients who were included in this study, 238 (77.3\%) (95\% CI 72.6-81.9) had successful TB treatment outcome, in which, 32(10.4\%) and 206(66.9\%) have been cured and completed their TB treatment respectively (Table 3 ).

\section{Factors associated with successful TB treatment outcome of the study participants}

In the Multi-variable logistic regression analysis; residence, mean baseline weight $(\mathrm{kg})$, functional status, and TB treatment side effect of the respondents were significantly associated with the successful TB treatment outcome $(P<0.05)$.

Accordingly, the odds of having successful $\mathrm{Tb}$ treatment outcome was $66 \%$ lower among TB/HIV coinfected patients who have been residing outside the Gondar town as compared to those who have been living in the Gondar town $[\mathrm{AOR}=0.44,95 \% \mathrm{CI}: 0.25-0.80]$.
Table 1 Socio-demographic and behavioral characteristics of respondents, Gondar University Hospital, 2016

\begin{tabular}{|c|c|c|c|c|}
\hline \multirow[t]{2}{*}{ Variables } & \multirow[t]{2}{*}{ Categories } & \multirow[b]{2}{*}{ Total } & \multicolumn{2}{|c|}{$\begin{array}{l}\text { Frequency of TB treatment } \\
\text { outcome, n (\%) }\end{array}$} \\
\hline & & & $\begin{array}{l}\text { Successful, } \\
\mathrm{n}(\%)\end{array}$ & Unsuccessful \\
\hline \multirow[t]{2}{*}{ Sex } & Male & 175 & $136(77.7)$ & $39(22.3)$ \\
\hline & Female & 133 & $102(76.7)$ & $31(23.3)$ \\
\hline \multirow[t]{4}{*}{ Age (years) } & $<15$ & 42 & 29(69.1) & 13(30.9) \\
\hline & $15-29$ & 81 & 70(77.8) & $20(22.2)$ \\
\hline & $30-44$ & 137 & 107(78.1) & $30(21.9)$ \\
\hline & $>44$ & 48 & $30(81.1)$ & $7(18.9)$ \\
\hline \multirow[t]{2}{*}{ Residence } & Gondar town & 229 & 186(81.2) & 43(18.8) \\
\hline & $\begin{array}{l}\text { Out of Gondar } \\
\text { town }\end{array}$ & 79 & $52(65.8)$ & $27(34.2)$ \\
\hline \multirow[t]{3}{*}{ Marital status } & Ever married & 206 & 164(79.6) & $42(20.4)$ \\
\hline & Unmarried & 57 & $42(73.7)$ & $15(26.3)$ \\
\hline & Not applicable & 45 & $32(71.1)$ & 13(28.9) \\
\hline \multirow[t]{4}{*}{ Education } & No education & 60 & 49(81.7) & $11(18.3)$ \\
\hline & Primary & 133 & 97(72.9) & $36(27.1)$ \\
\hline & $\begin{array}{l}\text { Secondary and } \\
\text { above }\end{array}$ & 100 & $82(82.0)$ & 18(18.0) \\
\hline & Not specified/NA) & 15 & $10(66.7)$ & $5(33.3)$ \\
\hline \multirow[t]{7}{*}{ Occupation } & Farmer & 27 & $20(74.1)$ & $7(25.9)$ \\
\hline & Merchant & 46 & $31(67 . .4)$ & 15(32.6) \\
\hline & Housewife & 43 & $37(86.0)$ & $6(14.0)$ \\
\hline & Student & 37 & $27(73.0)$ & $10(27.0)$ \\
\hline & Employed & 43 & $34(79.1)$ & $9(20.9)$ \\
\hline & Daily laborer & 97 & $80(82.5)$ & 17(17.5) \\
\hline & Note specified & 15 & $9(60.0)$ & $6(40.0)$ \\
\hline \multirow[t]{3}{*}{$\begin{array}{l}\text { Cigarette } \\
\text { smoking }\end{array}$} & $\begin{array}{l}\text { Non-smoking } \\
\text { history }\end{array}$ & 264 & 206(78.0) & $58(22.0)$ \\
\hline & Smoking history & 19 & 15(58.9) & $4(21.1)$ \\
\hline & Not specified & 25 & 17(68.0) & $8(32.0)$ \\
\hline
\end{tabular}

The Odds of having successful TB treatment outcome among TB/HIV co-infected patients having the mean base line weight $<43.7 \mathrm{~kg}$ was $49 \%$ lower as compared to patients who had $\geq 43.7 \mathrm{~kg}$ at the initiation of their TB treatment $[\mathrm{AOR}=0.51,95 \% \mathrm{CI}: 0.29-0.89]$. Similarly, the Odds of having successful TB treatment outcome was $77 \%$ lower among patients on bed ridden as compared to patients on working condition[AOR $=0.23,95 \% \mathrm{CI}$ : $0.1-$ 0.23]. Lastly, the odds of successful TB treatment outcome was $65 \%$ times lower among $\mathrm{Tb} / \mathrm{HIV}$ co-infected patients who complained $\mathrm{TB}$ treatment side effects than their counterparts $[\mathrm{AOR}=0.35,95 \% \mathrm{CI}$ : 0.12-0.98] (Table 4).

\section{Discussion}

Tuberculosis and HIV co-infection is one of the most public health challenges in sub-Saharan Africa [18]. It is 
Table 2 Concomitant, biological and medication related factors of the study participants, University of Gondar, 2016

\begin{tabular}{|c|c|c|c|c|}
\hline \multirow[b]{2}{*}{ Variables/factors } & \multirow[b]{2}{*}{ Categories } & \multirow{2}{*}{$\begin{array}{l}\text { Total } \\
N=308\end{array}$} & \multicolumn{2}{|c|}{ Tb treatment outcome, $n(\%)$} \\
\hline & & & Successful & Unsuccessful \\
\hline \multirow[t]{2}{*}{ CD4+ count at TB treatment entry } & $<200$ cells $/ \mathrm{mm}^{2}$ & 195 & $149(76.4)$ & $46(23.6)$ \\
\hline & $\geq 200$ cells $/ \mathrm{mm}^{2}$ & 113 & 89(78.8) & $24(21.2)$ \\
\hline \multirow[t]{2}{*}{ Mean base line weight $(\mathrm{kg})$ at TB treatment entry } & $<43.7$ & 132 & $92(69.7)$ & $40(30.3)$ \\
\hline & $\geq 43.7$ & 176 & 146(83.0) & $30(17.0)$ \\
\hline \multirow[t]{3}{*}{ Functional status } & Working & 163 & 136(83.4) & $27(16.7)$ \\
\hline & Ambulatory & 88 & $74(84.1)$ & 14(15.9) \\
\hline & Bedridden & 57 & 28(49.1) & 29(50.9) \\
\hline \multirow[t]{2}{*}{ INH prophylaxis } & Yes & 12 & 10(83.3) & $2(16.7)$ \\
\hline & no & 296 & $228(77.0)$ & $68(23.0)$ \\
\hline \multirow[t]{2}{*}{ CPT } & Yes & 274 & 214(78.1) & $60(21.9)$ \\
\hline & no & 34 & $24(70.6)$ & $10(29.4)$ \\
\hline \multirow[t]{2}{*}{ ART at TB treatment entry } & pre-ART & 188 & 143(76.1) & $45(23.9)$ \\
\hline & on ART & 120 & $95(79.2)$ & $25(20.8)$ \\
\hline \multirow[t]{2}{*}{ WHO staging } & III & 188 & 154(81.9) & $34(18.1)$ \\
\hline & IV & 120 & 84(70.0) & $36(30.0)$ \\
\hline \multirow[t]{2}{*}{ TB treatment history } & Yes & 77 & 59(76.6) & $18(23.4)$ \\
\hline & No & 231 & $179(77.5)$ & $52(22.5)$ \\
\hline \multirow[t]{2}{*}{ TB type } & Pulmonary & 219 & 175(79.9) & $44(20.1)$ \\
\hline & Extra-pulmonary TB & 89 & 63(78.8) & $26(29.2)$ \\
\hline \multirow[t]{3}{*}{ Category(case definition) of TB } & New TB cases & 221 & $169(76.5)$ & $52(23.5)$ \\
\hline & Relapse cases & 48 & $37(77.1)$ & $11(22.9)$ \\
\hline & Transfer in & 39 & $32(82.1)$ & $7(17.9)$ \\
\hline \multirow[t]{2}{*}{ Smear status $(n=219)$} & Positive & 47 & 38(80.9) & $9(19.1)$ \\
\hline & Negative & 172 & 133(77.3) & $39(22.7)$ \\
\hline \multirow[t]{2}{*}{ Treatment side effect } & Yes & 18 & 10(55.6) & $8(44.4)$ \\
\hline & No & 290 & 228(78.6) & $62(21.4)$ \\
\hline
\end{tabular}

recognized that both $\mathrm{TB}$ and HIV contributes to each other's progress [19] that affects the successful outcome of TB treatment, which ranges from $28.9 \%$ in Ethiopia [20] to $84.17 \%$ in India [21] and $86.0 \%$ in Malawi [22].

The overall successful TB treatment outcome in this study was $77.3 \%$. This result is higher than studies

Table 3 TB treatment outcome of the study participants, University of Gondar, 2016

\begin{tabular}{lllc}
\hline TB treatment outcome & Categories & Frequencies (n) & Percent (\%) \\
\hline Successful outcome & - & 238 & 77.3 \\
& Cured & 32 & 10.4 \\
& Completed & 206 & 66.9 \\
Unsuccessful outcome & - & 70 & 22.7 \\
& Defaulted & 37 & 12.0 \\
& Failed & 2 & 0.6 \\
& Death & 31 & 10.1 \\
\hline
\end{tabular}

conducted in India 67.2\% [23], Iran 64.0\% [24], Malaysia $53.4 \%$ [25], Ghana 64.0\% [26], Nigeria 48.8\% [27] and 62.7\% [28], and Ethiopia 28.9\% [20], 60.7\% [29], 70.8\% [17]. The possible explanation for this discrepancy might be associated with the difference in number of study participants involved in the study. On top of that, the handling of transfer out cases as one of the case definition of the TB treatment outcome in various studies indicated earlier may have also an effect on the reduction of the successful treatment outcome. But, in our cases, we did not include transferred out as one of the TB treatment outcome. Successful $\mathrm{Tb}$ treatment outcome may also be affected by the presence of more deaths and/or defaulters. It is evidenced by the studies conducted in Ethiopia where 11.4\% transferred out, 10.0\% defaulters and $17.4 \%$ deaths were recorded [29]; in Malaysia, $25.6 \%$ of the study participants were defaulters and the other $21.0 \%$ were death [25], which accounted a total of $46.6 \%$. 
Table 4 Bi-variable and multi-variable logistic regression analysis of factors associated with TB treatment outcome of the study participants, University of Gondar, 2016

\begin{tabular}{|c|c|c|c|c|c|}
\hline \multirow[t]{2}{*}{ Variable } & \multirow[t]{2}{*}{ Categories } & \multicolumn{2}{|c|}{ TB Treatment outcome, $n=308$} & \multirow[t]{2}{*}{$\operatorname{COR}(95 \% \mathrm{Cl})$} & \multirow[t]{2}{*}{ AOR $(95 \% \mathrm{Cl})$} \\
\hline & & Successful & Unsuccessful & & \\
\hline \multirow[t]{2}{*}{ Sex } & Male & 136 & 39 & 1 & \\
\hline & Female & 102 & 31 & $0.94(0.55,1.61)$ & \\
\hline \multirow[t]{4}{*}{ Age } & $<15$ & 29 & 13 & $0.45(0.16,1.22)$ & \\
\hline & $15-29$ & 59 & 22 & $0.54(0.22,1.32)$ & \\
\hline & $30-44$ & 110 & 27 & $0.82(0.34,1.94)$ & \\
\hline & $>44$ & 40 & 8 & 1 & \\
\hline \multirow[t]{2}{*}{ Residence } & Urban & 186 & 43 & 1 & 1 \\
\hline & Rural & 52 & 27 & $0.45(0.25,0.79)$ & $0.44(0.25,0.80) *$ \\
\hline \multirow[t]{4}{*}{ Educational status } & No education & 49 & 11 & 1 & \\
\hline & Primary & 97 & 36 & $0.61(0.28,1.29)$ & \\
\hline & Secondary and above & 82 & 18 & $0.10(0.45,2.34)$ & \\
\hline & Not specified/NA) & 10 & 5 & $0.45(0.13,1.58)$ & \\
\hline \multirow[t]{3}{*}{ Marital status } & Ever married & 164 & 42 & 1 & \\
\hline & Unmarried & 42 & 15 & $0.72(0.36,1.42)$ & \\
\hline & Not specified & 32 & 13 & $0.63(0.30,1.31)$ & \\
\hline \multirow[t]{2}{*}{ CD4 at TB Rx } & $<200$ cells $/ \mathrm{mm}^{3}$ & 149 & 46 & 1 & \\
\hline & $\geq 200 \mathrm{cell} / \mathrm{s} / \mathrm{mm}^{3}$ & 89 & 24 & $1.15(0.66,2.00)$ & \\
\hline \multirow[t]{2}{*}{ Mean baseline weight (Kg) } & $<43.7$ & 92 & 40 & $0.47(0.28-0.81)$ & $0.51(0.29-0.89) *$ \\
\hline & $>/=43.7$ & 146 & 30 & 1 & 1 \\
\hline \multirow[t]{3}{*}{ Functional status } & Working & 136 & 27 & 1 & 1 \\
\hline & Ambulatory & 74 & 14 & $1.05(0.52,2.12)$ & $1.29(0.62,2.67)$ \\
\hline & Bedridden & 28 & 29 & $0.19(0.09,0.37)$ & $0.24(0.12,0.48)^{*}$ \\
\hline \multirow[t]{2}{*}{ CPT } & Yes & 214 & 60 & 1 & \\
\hline & No & 24 & 10 & $0.67(0.31,1.49)$ & \\
\hline \multirow[t]{2}{*}{ ART } & Pre-ART & 143 & 45 & 1 & \\
\hline & On ART & 95 & 25 & $1.19(0.69,2.08)$ & \\
\hline \multirow[t]{2}{*}{ WHO stage } & III & 154 & 34 & 1 & \\
\hline & IV & 84 & 36 & $0.52(0.30,0.88)$ & \\
\hline \multirow[t]{2}{*}{ TB treatment history } & Yes & 59 & 18 & $0.95(0.52,1.76)$ & \\
\hline & No & 179 & 52 & 1 & \\
\hline \multirow[t]{2}{*}{ TB type } & Pulmonary & 175 & 44 & 1 & \\
\hline & Extra-pulmonary & 63 & 26 & $0.61(0.35,1.07)$ & \\
\hline \multirow[t]{2}{*}{ TB Treatment side effect } & Yes & 10 & 8 & $0.34(0.13,0.89)$ & $0.35(0.12,0.98) *$ \\
\hline & No & 228 & 62 & 1 & 1 \\
\hline
\end{tabular}

*significant at $p$-value $<0.05$

The successful TB treatment outcome which we found in the current study is nearly in agreement with studies conducted in Asian countries like in Indian; 75.0\% [30], $79.0 \%$ [31], and $80.0 \%$ [32]; in Vietnam 74.0\% [33]; in Africa, Zambia 80.0\% [34] and Ethiopia 80.5\% [35]. However, it is lower than the target of successful TB treatment outcome $(85 \%)$ recommended by the WHO [9]. Furthermore, the successful outcome of TB treatment found in India was $84.17 \%$ [21], Malawi $86 \%$ [22]; and in South Africa 82.2\% [36] which are higher than the outcome we found in the current study. Of course, the current finding showed substantial improvement compared to the two studies conducted in Ethiopia that ranges from 28.9 to $70.8 \%$ [17, 20].

The variation between our finding and results of others might be due to the presence of TB and HIV 
drug-drug interaction, patient's awareness on importance of adhering to TB treatment, and availability of facilities used to screen or diagnose TB in HIV/AIDS patients. In addition, a patient who is on TB-ART co-treatment will have higher pill burden and most likely will experience more side effects compared to those patients who are infected with TB only. These factors may lead to have low adherence to anti-TB drugs [37]. In addition, the substantial figures of defaulters and death recorded, and socio-economic conditions of the society in our cases may contribute for the low treatment outcome. These may support the reasons for many countries that are failing to achieve adequate successful TB treatment outcomes.

Being residing in the Gondar town is found to be significantly associated with the successful TB treatment outcome in our study which is in line with a study conducted in the same country $[17,38]$. The possible explanation for this condition is that being residing in the town might be positively associated with $\mathrm{TB}$ notification $[39,40]$ which lead to the successful TB treatment outcome of the patients. Secondly, it is evidenced by a study conducted in Jimma, Ethiopia, where a rural resident had lower TB treatment outcome [41]. In addition, a better awareness and information about TB and HIV/ AIDS might be more in the town than outside. Lastly, availability of health institutions at near to the vicinity in the town and fear of stigma and discrimination in outside of the town might be contributed for the successfulness as well as unsuccessfulness of TB treatment outcome.

Our finding revealed the presence of a significant association between mean baseline body weight $<43.7 \mathrm{~kg}$ measured at the commencement of $\mathrm{TB}$ treatment and the unsuccessful of TB treatment outcome. It is supported by a finding reported in Sothern Ethiopia in which survival of TB patients is lowered when one is HIV positive and has low baseline body weight during the initiation of TB treatment [1]. Another two studies conducted in Ethiopia also supported our finding, in which lower body weight of the patients at the initiation of TB treatment was significantly associated with unsuccessful outcome of TB treatment [42], and body weight at the initiation of ТВ treatment $(<35 \mathrm{~kg})$ was a significant risk factor for death at the time of $\mathrm{TB}$ treatment [43].

Like documented in the literature [35], finding of this study also showed that those co-infected patients who were on bedridden is significantly associated with the unsuccessful TB treatment outcome compared to those who were in playing and/or working (or active) condition. It is also consistent with a study conducted in Bair Dar, Ethiopia where more TB/HIV co-infected bedridden patients had unsuccessful TB treatment outcome or an increased risk of mortality during TB treatment [2]. In addition, as indicated in various literatures, being in bed ridden condition of the functional status among TB/HIV co-infected patients demonstrated unsuccessful TB treatment outcome [41, 44].

The possible explanation for this might be AIDS patients are likely to become malnourished from constantly being sick, from diarrhea that prevents absorption of nutrients, from loss of appetite and sores of mouth that make eating difficult, and from opportunistic infections. Similarly, weight loss and bedridden in TB patients might be explained partly by the loss of appetite and loss of energy by the disease itself and being immovable or inactive. Those patients who are in the very low body weight and bed ridden might be unable to work and care for themselves, live at home, and requires varying amount of assistance which may equivalent to institutional or hospital care from others and may lead to the progression of severity of diseases and even to death.

In this study, patients who had treatment side effect showed unsuccessful TB treatment outcome compared to those who had not experience the treatment side effect. This is in line with various studies in which they found that being co-infected with TB/HIV is significantly associated with unsuccessful treatment outcome [45, 46]. The possible reason could be related to pill burden, increase in adverse effect, drug-to-drug interaction, and drug induced toxicity, which reduces the adherence of the patients to their TB treatment regimen.

Apart from such important findings, this study is not without limitation. As common for secondary data based studies, important variables like CD4 level, distance to the health facility, and weight of the patients were incomplete from the records other than the baseline measures. In addition, this study may suffer from low sample size because of lack of complete patients' medical record.

\section{Conclusion}

This study showed that the successful anti-TB treatment outcome among TB/HIV co-infected patients who attended their treatment at the Gondar University Hospital TB DOTS clinic was below the target set by World Health Organization (WHO). Being residing in the Gondar town, having baseline body weight above the mean, able to perform usual work in or out of the house, and being free of treatment side effects were found to be factors associated with successful TB treatment outcome. Thus, we recommended that strengthening the integration of TB/HIV collaborative activities could improve the treatment outcome. In addition, improvise means of TB patients' follow up and tracing to keep them in contact with health professionals at service 
delivery point during treatment could increase the successfulness of TB treatment outcome.

\author{
Abbrevations \\ AFB: Acid fast bacilli; AIDS: Acquired immune deficiency syndrome; \\ AOR: Adjusted odds ratio; ART: Antiretroviral therapy; Cl: Confidence \\ interval; COR: Crude odds ratio; CPT: Co-trimoxazole prophylactic \\ treatment; DOTS: Directly observed treatment short course; HIV: Human \\ immunodeficiency virus; INH: Isoniazid; PTB: Pulmonary tuberculosis; \\ SPSS: Statistical package for social sciences; TB: Tuberculosis; WHO: World \\ Health Organization
}

\section{Acknowledgments}

We would like to thank University Gondar College of Medicine and Health Science, referral hospital administrative staffs for their unreserved support. Also we would like to thank the supervisors, data collectors, and the study participants.

\section{Funding}

This research received no specific grant from any funding agency in the public commercial, or not for profit sectors.

\section{Availability of data and materials}

The datasets used and/or analyzed during the current study available from the corresponding author on reasonable request.

\section{Authors' contribution}

YS who was the prinicipal author involved in the design, implementation of the study, data collection, statistical analysis, and drafted the manuscript. SA was involved in the design, and write up of the thesis. AF was involved in the design, performed statistical analysis, contributed to draft and critically review the scientific content of the manuscript. MG was involved in the design, implementation of the study, data collection and drafting of the manuscript. All authors read and approved the final manuscript.

\section{Authors' information}

YS and SA are working in University of Gondar referral hospital. AF is a lecturer and a researcher in the department of Epidemiology and Biostatistics, University of Gondar, Institute of Public Health, college of medicine and health science. MG is also a lecturer and a researcher in the school of biomedical science, college of medicine and health science, university of Gondar.

\section{Competing interest}

The authors declare that they have no competing interest.

\section{Consent for publication}

Consent to publish is secured from study participants.

\section{Ethics approval and consent to participate}

Ethical clearance was obtained from Institutional Review Board of the University of Gondar. Permission to conduct the research was obtained from regional health bureaus and respective Health offices. Written consent was obtained from the participants after explaining the purpose of the study. To ensure confidentiality, their name and other personal identifiers were not registered in the format. It was explained to the participants that the selection to the study was random and they have the right to not respond for questions that they are not comfortable with. Finally, the questionnaires were kept locked after data entry was completed.

\section{Author details}

'University of Gondar referral Hospital, Gondar, Ethiopia. ${ }^{2}$ Department of Epidemiology and Biostatistics, University of Gondar, Institute of Public Health, Gondar, Ethiopia. ${ }^{3}$ University of Gondar, College of Medicine and Health Science, School of Biomedical Sciences, Gondar, Ethiopia.
Received: 1 July 2016 Accepted: 2 February 2017

Published online: 08 February 2017

\section{References}

1. Shaweno D, Worku A. Tuberculosis treatment survival of HIV positive TB patients on directly observed treatment short-course in Southern Ethiopia: a retrospective cohort study. BMC Res Notes. 2012;5:682. Epub 2012/12/14.

2. Sileshi B, Deyessa N, Girma B, Melese M, Suarez P. Predictors of mortality among TB-HIV Co-infected patients being treated for tuberculosis in Northwest Ethiopia: a retrospective cohort study. BMC Infect Dis. 2013;13:297. Epub 2013/07/03.

3. Gray JM, Cohn DL. Tuberculosis and HIV coinfection. Semin Respir Crit Care Med. 2013;34(1):32-43. Epub 2013/03/06.

4. Bruchfeld J, Correia-Neves M, Kallenius G. Tuberculosis and HIV coinfection. Cold Spring Harb Perspect Med. 2015:5(7):a017871. Epub 2015/02/28.

5. Nglazi MD, Bekker LG, Wood R, Kaplan R. The impact of HIV status and antiretroviral treatment on TB treatment outcomes of new tuberculosis patients attending co-located TB and ART services in South Africa: a retrospective cohort study. BMC Infect Dis. 2015;15(1):536. Epub 2015/11/21.

6. Wondimeneh Y, Muluye D, Belyhun Y. Prevalence of pulmonary tuberculosis and immunological profile of HIV co-infected patients in Northwest Ethiopia. BMC Res Notes. 2012:5:331. Epub 2012/06/29.

7. Swaminathan S, Padmapriyadarsini C, Narendran G. HIV-associated tuberculosis: clinical update. Clin Infectious Diseases. 2010:50(10):1377-86. Epub 2010/04/15.

8. Sterling TR, Pham PA, Chaisson RE. HIV infection-related tuberculosis: clinical manifestations and treatment. Clin Infectious Diseases. 2010;50 Suppl 3:S223-30. doi:10.1086/651495

9. World Health Organization. Global tuberculosis report 2013. In: WHO/HTM/ TB/2013.11. Geneva: WHO; 2013. http://whqlibdoc.who.int/hq/2013/WHO HTM_TB_2013.11.pdf. Accessed Jan 2016. 2013.

10. Garedew L, Mihret A, Mamo G, Abebe T, Firdessa R, Bekele Y, et al. Strain diversity of mycobacteria isolated from pulmonary tuberculosis patients at Debre Birhan Hospital, Ethiopia. Int J Tuberculosis Lung Dis. 2013;17(8):1076-81. doi:10.5588/ijtld.12.0854.

11. World Health Organization. Global Plan to Stop TB 2011-2015. Davos: WHO; 2006. whqlibdoc.WHO.int/publications/2010/97 89241500340_eng.pdf. Accessed Feb 2016

12. Federal Ministry of Health of Ethiopia (FMOH). Tuberculosis, Leprosy and TB/HIV Prevention and Control Programme Manual. 4th edn. Addis Ababa; 2008.

13. World Health Organization. Improving the diagnosis and treatment of smear negative pulmonary and extra-pulmonary tuberculosis among adults and adolescents: recommendations for HIV-prevalent and resourceconstrained settings. In: WHO/HTM/TB/2007.379 WHO/HIV/2007.01. 2007.

14. Berhe G, Enqueselassie F, Hailu E, Mekonnen W, Teklu T, Gebretsadik A, et al. Population-based prevalence survey of tuberculosis in the Tigray region of Ethiopia. BMC Infect Dis. 2013;13:448. Epub 2013/10/01.

15. Yen YF, Yen MY, Lin YS, Lin YP, Shih HC, Li LH, et al. Smoking increases risk of recurrence after successful anti-tuberculosis treatment: a population-based study. Int J Tuberculosis Lung Dis. 2014;18(4):492-8. doi:10.5588/ijtld.13.0694.

16. Chuang H, Su C, Liu H, Feng P, Lee K, Chuang K, et al. Cigarette smoke is a risk factor for severity and treatment outcome in patients with culture positive tuberculosis. Ther Clin Risk Manage. 2015;11:1539-44.

17. Belayneha M, Giday K, Lemma H. Treatment outcome of human immunodeficiency virus and tuberculosis co-infected patients in public hospitals of eastern and southern zone of Tigray region, Ethiopia. Braz J Infect Dis. 2015;19(1):47-51.

18. Belay M, Bjune G, Abebe F. Prevalence of tuberculosis, HIV and TB-HIV co-infection among pulmonary tuberculosis suspects in a predominantly pastoralist area, northeast Ethiopia. Glob Health Action. 2015;8:27949. Epub 2015/12/23

19. del Amo S, Perez-Hoyos I, Aguado H, Diez M, Castilla J, Porter K. Impact of tuberculosis on HIV disease progression in persons with well-documented time of HIV seroconversion. J Acquir Immune Defic Syndr. 2003;33:184-90.

20. Fiseha T, Gebru T, Gutema H, Debela Y. Tuberculosis treatment outcome among HIV co-infected patients at Mizan-Aman general hospital, Southwest Ethiopia: a retrospective study. J Bioeng Biomed Sci. 2015;2015:1-4.

21. Tripathi SB, Kapadia VK. Treatment outcome of tuberculosis in HIV seropositive patients: an experience of Southeast Region of Ahmedabad. Cough. 2015;101:84.17. 
22. Tweya HFC, Phiri S, Ben-Smith A, Fenner L, Jahn A, et al. Comparison of treatment outcomes of New smear-positive pulmonary tuberculosis patients by HIV and antiretroviral status in a TB/HIV clinic, Malawi. PLOS One. 2013;8(2):e56248. doi:10.1371/journal.pone.0056248.

23. Agarwal U, Kumar A, Behera D. Profile of HIV associated tuberculosis at a tertiary institute in setting of free anti-retroviral therapy. J Assoc Physicians India. 2009;57:685-90. Epub 2010/03/25.

24. Tabarsi P, Mirsaeidi SM, Amiri M, Mansouri SD, Masjedi MR, Velayati AA. Clinical and laboratory profile of patients with tuberculosis/HIV coinfection at a national referral centre: a case series. Eastern Mediterranean Health $\mathrm{J}=\mathrm{La}$ revue de sante de la Mediterranee orientale $=$ al-Majallah al-sihhiyah li-sharq al-mutawassit. 2008;14(2):283-91. Epub 2008/06/20.

25. Ismail I, Bulgiba A. Determinants of unsuccessful tuberculosis treatment outcomes in Malaysian HIV-infected patients. Preventive Med: Suppl. 2013;57:S27-30.

26. Ansa GA, Walley JD, Siddiqi $K$, Wei $X$. Assessing the impact of TB/HIV services integration on TB treatment outcomes and their relevance in TB/ HIV monitoring in Ghana. Infect Dis Poverty. 2012;1:13.

27. Ofoegbua OS, Odume BB. Treatment outcome of tuberculosis patients at National Hospital Abuja Nigeria: a five year retrospective study. S Afr Family Pract. 2015:57(1):50-6. ISSN 2078-6190 EISSN 2078-6204.

28. Duru CB, Uwakwe KA, Nnebue CC, Diwe KC, Merenu IA, Emerole CO, et al. Tuberculosis treatment outcomes and determinants among patients treated in hospitals in Imo State, Nigeria. Open Access Library J. 2016;3:e2754. http://dx.doi.org/10.4236/oalib.1102754.

29. Ejeta E, Birhanu T, Wolde T. Tuberculosis treatment outcomes among tuberculosis/human immuodefiecncy coinfected cases treated under directly observed treatment of short course in western Ethiopia. AcademicJurnals. 2014;6(8):164-71.

30. Shastri S, Naik B, Shet A, Rewari B, De Costa A. TB treatment outcomes among TB-HIV co-infections in Karnataka, India: how do these compare with non-HIV tuberculosis outcomes in the province? BMC Public Health. 2013;13:838. http://www.biomedcentral.com/1471-2458/13/838.

31. Deshmukh R, Kumar A, Gupta RS, Sachdeva KS, Sreenivas AN, Shah A. Treatment outcomes among HIVTB co-infected new patients and new smear positive TB patients, India. Melbourne: AIDS: 20th international AIDS Conference; 2014

32. Ambadekar NN, Zodpey SP, Soni RN, Lanjewar SP. Treatment outcome and its attributes in TB-HIV co-infected patients registered under revised national TB control program: a retrospective cohort analysis. Public Health. 2015;129:783e9.

33. Huyen TTT, Nhung NV, Shewade HD, Hoa NB, Harries AD. Collaborative activities and treatment outcomes in patients with HIV-associated tuberculosis in Viet Nam. Public Health Action. 2016;6(1):8-14

34. Kapata N, Chanda-Kapata P, Grobusch M, O'Grady J, Schwank S, Bates M, et al. Scale-up of TB and HIV programme collaborative activities in Zambia-a 10year review. Trop Med Int Health. 2012;17(6):760-6.

35. Balcha TT, Skogmar S, Sturegard E, Bjorkman P, Winqvist N. Outcome of tuberculosis treatment in HIV-positive adults diagnosed through active versus passive case-finding. Glob Health Action. 2015;8:27048. doi:10.3402/ gha.v8.

36. Jacobson KB, Moll AP, Friedland GH, Shenoi SV. Successful tuberculosis treatment outcomes among HIV/TB coinfected patients DownReferred from a district hospital to primary health clinics in rural South Africa. PLoS One. 2015;10(5):e0127024. doi:10.1371/journal.pone.012702.

37. Gebremariam MK, Bjune GA, Frich JC. Barriers and facilitators of adherence to TB treatment in patients on concomitant TB and HIV treatment: a qualitative study. BMC Public Health. 2010;10:651. doi:10.1186/471-2458-10-651.

38. Gebrezgabiher G, Romha G, Ejeta E, Asebe G, Zemene E, Ameni G. Treatment outcome of tuberculosis patients under directly observed treatment short course and factors affecting outcome in Southern Ethiopia: a five-year retrospective study. PLoS One. 2016;11(2):e0150560. doi:10.1371/journal.pone.

39. Harling G, Castro MC. A spatial analysis of social and economic determinants of tuberculosis in Brazil. Health Place. 2014;25:56-67.

40. Itogo N, Hill PC, Bissell K, Harries AD, Viney K, Gounder S. Tuberculosis notifications, characteristics and treatment outcomes: urban vs. rural Solomon Islands, 2000-2011. Public Health Action. 2014;4(2):S25-8.

41. Gesesew H, Tsehaineh B, Massa D, Tesfay A, Kahsay H, Mwanri L. The role of social determinants on tuberculosis/HIV co-infection mortality in southwest Ethiopia: a retrospective cohort study. BMC Res Notes. 2016;12(9):89. doi:10.1186/s13104-016-1905-x).
42. Biruk M, Yimam B, Abrha H, Biruk S, Amdie FZ. Treatment outcomes of tuberculosis and associated factors in an Ethiopian University Hospital. Hindawi Publishing Corporation, Advances in Public Health; 2016. 2016((Article ID 8504629):9 pages)):9 pages.

43. Getahun B, Ameni G, Biadgilign S, Medhin G. Mortality and associated risk factors in a cohort of tuberculosis patients treated under DOTS programme in Addis Ababa, Ethiopia. BMC Infect Dis. 2011;11:127.

44. Abrha H, Tsehayneh B, Massa D, Tesfay A, Kahsay H. Survival experience and its predictors among TB/HIV Co-infected patients in Southwest Ethiopia. Epidemiol (Sunnyvale). 2015;5:191. doi:10.4172/2161-1165.1000191.

45. NorRonaidi NM, Mohd NS, Mohammad ZW, Sharina D, Rosmawati NH. Factors associated with unsuccessful treatment outcome of pulmonary tuberculosis in Kota Bharu, Kelantan. Malaysian J Public Health Med. 2011;11(1):6-15.

46. Sanchez M, Bartholomay P, Arakaki-Sanchez D, Enarson D, Bissell K, Barreira D, et al. Outcomes of TB treatment by HIV status in national recording systems in Brazil, 2003-2008. PLoS One. 2012;7(3):e33129. doi:10.1371/journal.pone.0033129.

\section{Submit your next manuscript to BioMed Central and we will help you at every step:}

- We accept pre-submission inquiries

- Our selector tool helps you to find the most relevant journal

- We provide round the clock customer support

- Convenient online submission

- Thorough peer review

- Inclusion in PubMed and all major indexing services

- Maximum visibility for your research

Submit your manuscript at www.biomedcentral.com/submit
C) Biomed Central 